1999-01-01

\title{
The Inter-Organisational Relationships in Irish Tourism: the Example of Lough Derg
}

\author{
Kevin Griffin \\ Technological University Dublin, kevin.griffin@tudublin.ie
}

Follow this and additional works at: https://arrow.tudublin.ie/tfschhmtart

Part of the Tourism Commons

\section{Recommended Citation \\ This Article is brought to you for free and open access by the School of Tourism \& Hospitality Management at ARROW@TU Dublin. It has been accepted for inclusion in Articles by an authorized administrator of ARROW@TU Dublin. For more information, please contact arrow.admin@tudublin.ie, aisling.coyne@tudublin.ie, gerard.connolly@tudublin.ie.}

Griffin, K. (1999) 'Interorganisational Relationships in Irish Tourism'. In Irish Geography - Journal of the Geographical Society of Ireland, Vol. 32 (1), pp 58-72. DOI: 10.21427/d7drOh

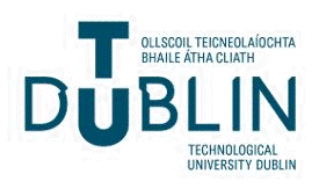




\title{
The Inter-organisational Relationships in Irish Tourism: the example of Lough Derg
}

\author{
Kevin A. Griffin \\ Dublin Institute of Technology
}

\begin{abstract}
The data presented in this paper are drawn from research work carried out by the author into the operation and organisation of Irish tourism at a local level. In carrying out this work 104 tourism operators were surveyed in detail in order to assess their attitudes and opinions on a number of issues. The two dominant themes which emerged from this research were the highly varied nature of the tourism operations and the multitude of service providers with whom they interact. The purpose of this paper is to illustrate this diversity of Inter-organisational Relationships (IORs) and to propose an organisational structure which may aid in minimising such complexities.
\end{abstract}

Key Index Words: Tourism, Ireland, Inter organisational Relationships.

\section{Introduction}

In recent years Irish tourism has expanded dramatically. Between 1988 and 1997 foreign exchange earnings from this industry rose from IR£841 million to IR£2105 million. In the same period, numbers of visitors increased from 2.4 million to 5.0 million. Current estimates predict that this growth rate will continue for the foreseeable future (Bord Fáilte, 1998).

Research into the current state and future potential of Irish tourism include studies of employment (BDO Simpson Xavier Consulting, 1998), general reviews of marketing policy (Irish Tourist Board, 1998), strategic frameworks for tourism growth (Irish Tourist Industry Confederation, 1998) and examinations of Irish tourism policy and performance, mainly in economic terms (Deegan and Dineen, 1997). Even at the level of Government policy generation, very little attention has been focused outside the economic aspects of the industry. The First and Second Operational Programme for Tourism and similar reports (Department of Tourism and Transport, 1992; 1994), examined tourism as an industry comprising a number of economic functions such as the provision of transport, accommodation and activity. Aside from their income generation and potential for job creation, little analytical investigation has been carried out.

In attempting to address this neglect, this paper will deal with the Inter-organisational Relationships (IORs) between individual tourism operators and the myriad tourism organisations and agencies. To draw together some key concepts and ideas relating to the IORs in Irish tourism, the industry will be examined in a schematic manner based on data relating to the Lough Derg area of the river Shannon. It is suggested, however, that the relationships indicated may apply to Irish tourism in general.

\section{Inter-organisational Relationships}

Tourism represents a highly complex economic and social phenomenon which affects millions of people all over the world. The industry entails a complex network of businesses engaged in the provision of accommodation, catering, travel facilities, services and entertainment of the tourist.

"It is only within recent years [however] that scholars have begun to examine the richness and variety of this [tourism] phenomenon ... a major industry that is destined to endure, providing personal satisfaction as well as global economic and social benefits ... an activity [which] has 
been an integral part of human behaviour throughout history, taking on many forms as appropriate to a particular time and place" (Smith, 1992: 197)

Each enterprise involved in tourism fulfils a broad variety of functions for a highly varied clientele and in so doing, each enterprise or operator deals with a wide variety of organisations, individuals and groups whose purpose can vary from advertising to promotion, to policy making and business advice.

According to Hall (1991) "all organisations have relationships with other organisations. Some are relatively trivial while others are of utmost importance for the parties involved" (p.216). In any environment these IORs are a product of the range of organisations involved and in order to understand them further, it is important to investigate them in detail. To provide a framework for this paper, Hall's (1991) work on the evaluation of IORs has been adopted. This work suggests a number of indices which can be useful for the evaluation of relationships.

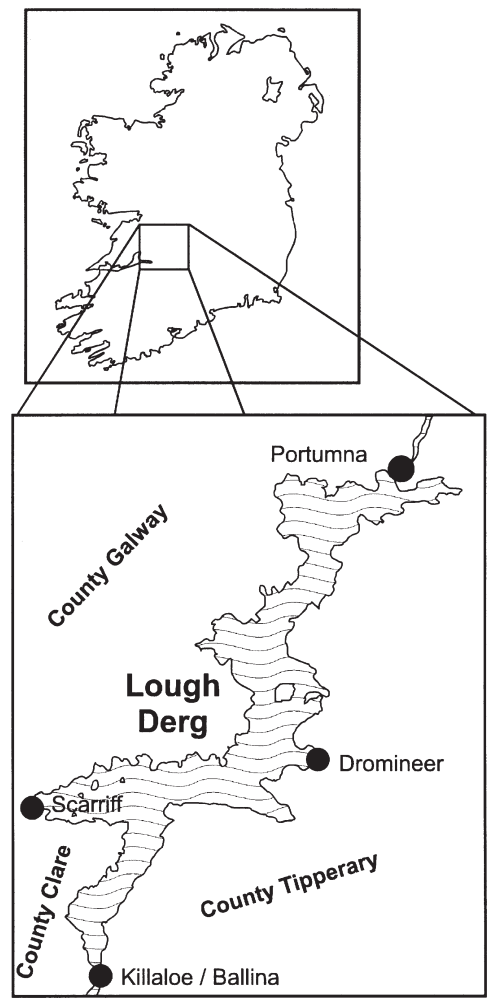

Figure 1: study area.
(1) The importance of interaction. The importance each of the organisations place on their relationship is a good indication of the need and success of the interaction.

(2) The degree of conflict/co-operation involved in the interaction. Engaging in contact to pursue common goals is seen as a main reason for maintaining IORs, however, if the purpose is to oppose each other, interaction will not usually be maintained in the long-term.

(3) The frequency of interaction. The regularity of communication between organisations is a good indication of the importance which both parties place on the IOR.

(4) The formalisation of relationship in the interaction. In many cases, contact is at an informal level. Hall suggests that the level of agreement formalisation in relation to interaction is an indicator which may be used in evaluating IORs.

(5) The reciprocity of transaction within the interaction. The flow of interaction may be unidirectional or reciprocal. Where interaction is reciprocal, IORs will be more successful. (Hall, 1991).

Throughout the following discussion, IORs will be examined using a number of these indices.

\section{Lough Derg Tourism Product}

The study area is the environs of Lough Derg, which is the largest and most southerly lake on the river Shannon, covering approximately 13,000 hectares (Figure 1). Justification for selecting this study area lies in the fact that its tourism identity is based on an identifiable and developing tourism product (Flanagan, 1991).

To provide an understanding of the complex range of industries involved in the Lough Derg tourism product, Figure 2 is a representation of the relationship between tourists to the area and their destination. The data upon which this model is based are drawn from the author's research into tourism in the area and 


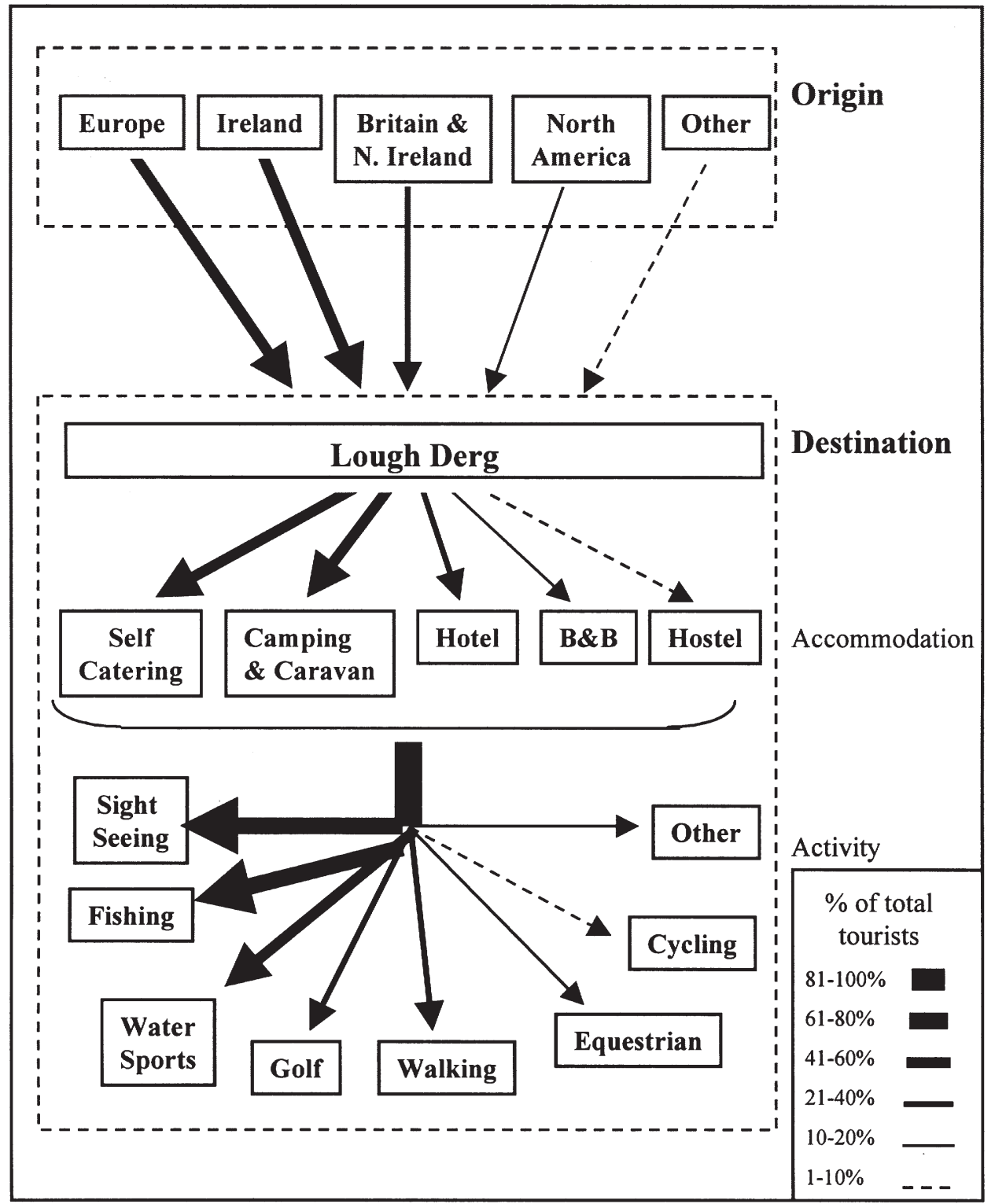

Figure 2: Characteristics of Lough Derg tourism.

represent the state of tourism as presented by the tourism operators in the region during the 1993-94 tourism season. At the time of this survey, Lough Derg tourism was dominated by the European market, which accounted for 52.4 percent of overseas tourism business in the area. The European share of the national market at the time was only 24.8 percent. Domestic tourism accounted for 29.5 percent of total Lough Derg business, which was close to the national figure of 36.2 percent, but, whereas the national overseas figures were dominated by the combined British and Northern Ireland market (accounting for 60.9 percent of all business) these customers only accounted for 36.9 percent of Lough Derg tourism (Bord Fáilte, 1995, Griffin, 1995). The variation of these data from the national situation illustrates the national heterogeneity of the industry - Lough Derg is more dependant on European and less dependant on British 
tourism than is the national case and this is possibly related to the nature of the tourism product - the high numbers of Europeans would appear to be attracted by the activities available (particularly water-based) in the study area.

The ranking of accommodation enterprises is calculated using data on the peak season occupancy levels of the 61 accommodation enterprises which were surveyed. Self-Catering accommodation is by far the most popular type, accounting for 46.7 percent of peak season supply. This is followed by camping and hotel accommodation which represent 19.5 and 17.8 percent respectively. While 21.0 percent of all tourism operators in the area are in the bed and breakfast sector, this grouping only accounts for only 13.6 percent of accommodation provision. Hostel accommodation, which is in short supply in the area, is the least important sector, accounting for only 2.4 percent of peak season provision.

In line with national data, the most important activity in the area is sightseeing. Fishing is the second most important activity, reflecting the importance of the lake as a focus for tourism and this is further emphasised by the importance of water-sports. Other important activities are golf, walking, equestrian pursuits and cycling.

Overall this model provides a simple graphic representation of some of the elements of tourism at a local level in Ireland, thereby, illustrating the complexity of the industry and the difficulty of providing for coherent planning and development, particularly at an organisational level (Griffin, 1995).

\section{Lough Derg Tourism Organisations}

In addition to the broad range of tourism operators, there are a wide variety of tourism organisations with which they deal. Data from the survey of 104 tourism operators around Lough Derg are presented in Table 1 and includes the organisations which the operators identified as having an influence on the organisation of tourism. In order to help understand the functions and operations of the various organisations they are classified using a number of criteria including:

scale (i.e. national, regional or local) and diversity of function (i.e. whether the organisation deals

with all aspects of tourism enterprise or just a specific sphere).

Also identified are:

organisations which deal with a single type of business and organisations which are not concerned exclusively/primarily with tourism.

Bord Fáilte, for example, is a national organisation that deals with all types of tourism operator. The Ireland Accommodation Guide also has a national membership base, but this agency deals solely with accommodation enterprises. The Tourist Menu is another national organisation, which is limited in function: in this case to catering enterprises. Examples of local groups are Tipperary Lakeside and East Clare LEADER group. Both of these organisations deal with a range of tourism enterprises, but, as denoted by the asterisk, they do not deal exclusively with tourism enterprises, having a much broader development brief.

From this table it can be seen that tourism organisations may be categorised using various criteria. One criterion which appears to have a major influence on the perception of, and thus, contact with an organisation is the priority which tourism operators place on its work. This is related to the first two of Hall's indices outlined above - i.e. importance of interaction and degree of co-operation. For the purpose of clarity five (non-hierarchical) categories may be considered. 
Table 1: Lough Derg tourism organisation/advertising matrix.

\begin{tabular}{|c|c|c|}
\hline \multicolumn{3}{|c|}{ Function } \\
\hline Scale & Universal Function & Specific Function \\
\hline National & $\begin{array}{l}\text { Bord Fáilte } \\
\text { Irish Tourism Industry } \\
\text { Confederation }\end{array}$ & $\begin{array}{l}\text { CERT } \\
\text { Coach Tourism Council } \\
\text { Irish Hotels Federation } \\
\text { OPW* } \\
\text { TEAGASC* } \\
\text { Accommodation Guide } \\
\text { Convention Bureau of Ireland } \\
\text { Restaurants: } \\
\text { National Guide to Restaurants } \\
\text { Tourist Menu } \\
\text { Hotels \& Guest houses } \\
\text { Town \& Country Homes } \\
\text { Self-Catering: } \\
\underline{\text { Self-Catering Guide }} \\
\text { Bed \& Breakfast/Guesthouse } \\
\underline{\text { Irish Farm Holidays }} \\
\underline{\text { Friendly Homes of Ireland }} \\
\text { Be our Guest } \\
\underline{\text { Hidden Ireland }} \\
\text { Camping/Caravan: } \\
\text { Caravan \& Camping guide }\end{array}$ \\
\hline Regional & $\begin{array}{l}\text { Western Regional Tourism Org. } \\
\text { Shannon Development* } \\
\text { Regional Tourism Partnership }\end{array}$ & \\
\hline Sub-Regional / Lake & $\begin{array}{l}\text { Lough Derg Working Group* } \\
\text { Lough Derg Marketing Group } \\
\text { Lough Derg Pleasure Lake }\end{array}$ & \\
\hline Local & $\begin{array}{l}\text { Tipperary Lakeside* } \\
\text { Tourism Information Office } \\
\text { East Clare LEADER* } \\
\text { Heritage Centre } \\
\text { Tidy Towns* } \\
\text { Chamber of Commerce* } \\
\text { Development Association* } \\
\text { Community Council* } \\
\text { Fishing Group }\end{array}$ & \\
\hline
\end{tabular}

* Denotes organisation is not exclusively a tourism organisation

Underlined organisations are those that deal with a single type of business 
Primary organisations. This category includes organisations that must be contacted by an operator. Mainly referring to Bord Fáilte, the relevant Regional Tourism Organisation and the local Tourist Information Office, these are organisations which must be contacted in order to achieve official recognition (i.e. to achieve Bord Fáilte approval) or to operate within official tourism networks.

Specialised organisations. A number of organisations deal with tourism enterprises of a specific nature. This category includes business-specific organisations such as Bórd Fáilte's Ireland Accommodation Guide, the Bord Fáilte Self Catering Guide and the Ballygowan Guide to Restaurants.

Elite organisations. This category consists of organisations that are highly specific and selective in the nature of their membership and includes groups such as Hidden Ireland or the Tourist Menu. These are the type of organisation to which many operators aspire.

Secondary organisations. This broad category includes the range of non-essential support/promotional organisations that are non-specific in their membership criteria. This grouping includes such tourismspecific organisations as the Irish Tourist Industry Confederation, Shannon Tourism Partnership or Tipperary Lakeside, but also includes local development groups and LEADER.

Functional organisations. This final group includes organisations that have a highly specialised, practical function in relation to tourism. Examples include CERT (the State Hotel and Tourism Training Agency) or TEAGASC (the Agricultural and Food Development Authority, but also organisations such as the OPW (Office of Public Works). These organisations are not exclusively tourism organisations but are contacted by operators for specific purposes.

\section{Lough Derg IORs}

To produce a generalised statement that adequately deals with a vast number of relationships is a far from simple task. Table 2 represents 329 individual relationships between 104 tourism operators and the range of tourism organisations outlined in Table 1. As such it can only hope to summarise the data in very general terms. The table lists a number of organisations and groups, firstly, indicating the percentage of all operators who were in contact with each organisation, and secondly, assigning to each organisation a value based on how frequently they were contacted by the operators in question. A value of 3 in the second column indicates regular contact and a value of 1 indicates irregular contact. It must be pointed out that this figure is simply a measure of regularity of contact, and does not indicate the quality of that interaction.

In all, 82.7 percent of the interviewed operators were in contact with some tourism organisation. A total of 71.2 percent of operators were in contact with two, and 54.8 percent were in contact with three or more organisations. The organisations which were contacted only on an 'irregular basis' (contact index of 1.00 to 1.49) include the Coach Tourism Council, the Irish Tourism Industry Confederation, the Convention Bureau of Ireland, Nenagh Heritage Centre (a local museum and visitor centre which mounts displays of local and regional interest) and the Town and Country Homes organisation. These are mainly national organisations that were contacted by only a small number of operators. The four organisations with the lowest contact index (value of 1.00) were each contacted by fewer than 2.8 percent of operators. The Town and Country Homes organisation, also in this category, was contacted by 7.7 percent of operators. Three of these organisations are highly specialised and most operators would have little interest or reason to contact them. These are the Coach Tourism Council, Irish Tourism Industry Confederation and the Convention Bureau of Ireland. The exceptions to this are the Heritage Centre (which is contacted by 1.9 percent of operators) and the Town and Country Homes organisation. For individual operators, these two organisations have an advertising function with no real advisory role. Thus, operators (on an irregular basis) either hand in their advertising literature (in the case of the Heritage Centre), or pay their annual subscription, neither of these acts require or result in further regular contact. 
Table 2: Summary of All IORs: Contact with each organisation.

\begin{tabular}{lrc}
\hline Organisation & Percent of operators Contact Index \\
\hline LEADER group & 2.8 & 2.66 \\
Expert Group/Organisation & 4.8 & 2.40 \\
Local Tourist Information Office & 60.6 & 2.31 \\
Hidden Ireland & 3.8 & 2.00 \\
Shannon Development/ Regional Tourism Organisation & 67.3 & 1.88 \\
Tipperary Lakeside & 28.8 & 1.86 \\
Lough Derg Marketing Group & 26.0 & 1.81 \\
CERT & 9.6 & 1.80 \\
Friendly Homes of Ireland & 4.8 & 1.80 \\
Lough Derg Working Group & 17.3 & 1.77 \\
Irish Farm Holidays & 5.8 & 1.66 \\
OPW & 9.6 & 1.60 \\
Bord Fáilte & 56.7 & 1.59 \\
Irish Hotel Federation & 6.7 & 1.57 \\
Shannon Tourism Partnership & 15.4 & 1.56 \\
TEAGASC & 5.8 & 1.50 \\
Town and Country Homes & 7.7 & 1.25 \\
Heritage Centre & 2.8 & 1.00 \\
Convention Bureau of Ireland & 1.9 & 1.00 \\
ITIC & 1.9 & 1.00 \\
Coach Tourism Council & 1.0 & 1.00 \\
\hline
\end{tabular}

\section{Contact Index}

$2.60-3.00=$ Regular Contact

$2.10-2.59=$ Fairly Regular Contact

$2.00-2.09=$ Occasional Contact

$1.50-1.99=$ Fairly Irregular Contact

$1.00-1.49=$ Irregular Contact

At the other end of the contact index scale are the organisations that were contacted on a 'regular' or 'fairly regular' basis (contact index of 2.60 to 3.00 and 2.10 to 2.59 respectively). The East Clare LEADER group, with a contact index of 2.66 , is the only organisation which was contacted on a 'regular' basis. While relatively new, when this survey was carried out, this organisation was already active in promoting tourism in the Scarriff area, organising business courses and workshops for tourism operators, and being instrumental in the establishment of a local tourism co-operative. Regular contact with this organisation was only by operators with enterprises in the geographical catchment area of Scarriff (see figure 1) and thus, there was only a small (if active) number of individuals involved (only 2.8 percent of all operators).

There are a number of groups/organisations that were contacted on a 'fairly regular' basis. These include the relevant local Tourist Information Office (which was contacted by a large percentage of individual operators - 60.6 percent ), and also a number of organisations which are included in the table under the title of 'Expert Groups/Organisation'. Included in this wide-ranging category are specialised organisations such as: the ESB; the Shannon Regional Fisheries Board; the Irish Boat Rental Association; the Independent Holiday Hostel Association; and Tourist Information Offices other than the local one. As none of these organisations appeared more than once in the survey and their level of contact is similar, they were dealt with as a single group. 
A number of reasons may be proposed as to why organisations were contacted on a fairly regular basis. As suggested above they all appear to carry out work directly relevant to the day-to-day workings of specific tourism enterprises. The local Tourist Information Office makes bookings, advertises and promotes local enterprises on a daily basis and carries out work which has a direct impact on the business of an operator. A number of the other organisations also provide a regular service to operators, albeit of a very specific nature. The Regional Fisheries Board, for example, is only of interest to operators with a major interest in fishing, the Boat Rental Association is only of interest to those providing cruisers for hire, and the Independent Holiday Hostel Association deals only with its recognised members.

The middle category in this contact index scale is the narrow band of 'occasional contact', with values from 2.00 to 2.09. The Hidden Ireland Group is the only member of this category and as with a number of organisations in the 'fairly regular' category, the Hidden Ireland group provides regular information to, and answers queries from, its members.

The largest category in this table is the 'fairly irregular' index value ranging from 1.50 to 1.99 . Following from the characteristics of the other categories it may be proposed that organisations at the upper end of this group would be those providing the most practical service to the operators who contacted them. This hypothesis applies in the case of Shannon Development and the Western Regional Tourism Organisation, Tipperary Lakeside Group and the Lough Derg Marketing Group: these organisations carry out extensive marketing and promotional activity, are in contact with operators both to gather and to disseminate information and were also contacted by large percentages of the operators (see first column of data).

The fourth member of this group is CERT with a contact index 1.80. The main dealings which operators have with CERT is to organise training and work experience for students in the various businesses. Friendly Homes of Ireland (1.80) Irish Farm Holidays (1.66) and the Shannon Tourism Partnership (1.56) are all advertising groups, which, it would appear, have less contact with operators. In these three cases, the most common experience is for businesses to pay membership, and typically that is the only contact between operator and organisation. Only in a minor number of cases was there more frequent contact. The Lough Derg Working Group (1.77), OPW (1.60), Irish Hotels Federation (1.57) and TEAGASC (1.50) are all organisations that have an ancillary advisory role regarding tourism. Only in particular cases did operators contact these groups, and when this happened it was on a 'fairly irregular' basis.

The only member of this 'fairly irregular' group that has not already been dealt with is Bord Fáilte, which has a contact index rating of 1.59. This low score may initially appear out of character for the National Tourism Organisation (NTO), however, in theory, operators' dealings with them ought to be through the appropriate Regional Tourism Organisation. In view of this, the level of contact is quite high, with 56.7 percent of operators claiming to directly contact Bord Fáilte (although this is on a 'fairly irregular' basis). In most cases this contact is to pay annual registration, to enquire about or advertise in a particular publication.

Arising from this basic analysis, a number of generalisations may be made about the organisations that are contacted by tourism operators. The organisations which are contacted most regularly by large numbers of operators can be seen to be those which have achieved some of the fundamental requirements of IORs outlined by Simmons, (1994) - they are goal oriented; democratic; integrate their goals into mainstream planning and carry out their work in a systematic and well-planned manner.

\section{Modelling Lough Derg IORs}

Figure 3 presents more value-specific data on the IORs of tourism. In developing the structure of the model, the work of a number of authors on organisational theory was adopted. 


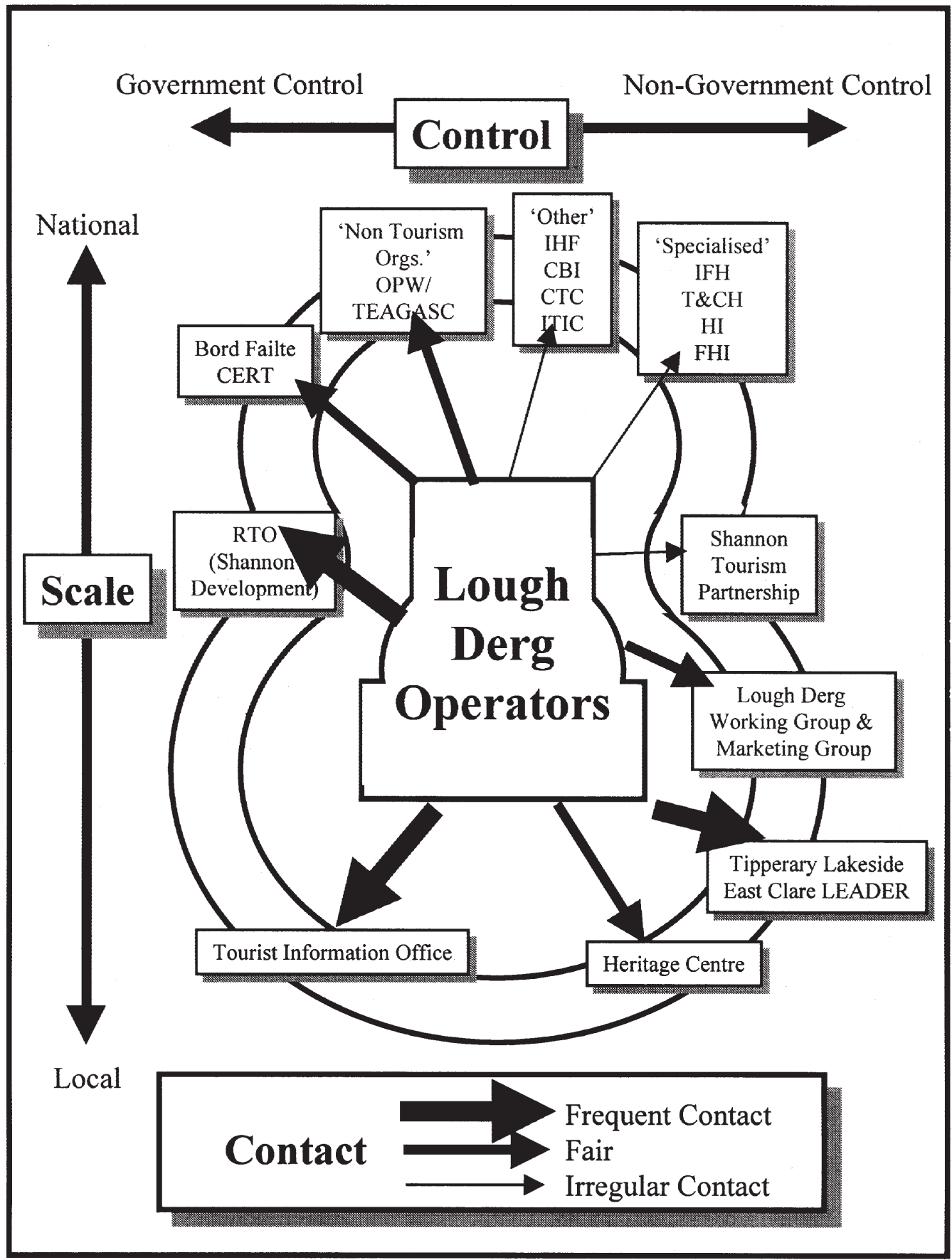

Figure 3: Frequency of IORs in Lough Derg tourism. 
The basic structure is a simplified version of Mintzbergh's 'cast of players' as outlined by Clegg (1990). Clegg illustrates the interaction between organisations in terms of a twofold division of these organisations into the 'internal' and the 'external coalition'. In this model the 'internal coalition' contains the Lough Derg tourism operators and the 'external coalition' contains the organisations with which they interact.

In order to classify the various elements of the 'external coalition', two axes are used. In this case, the two axes use attributes influenced by Pearce (1992) in his 'dimensions of tourism organisation'. In this instance 'scale' and 'degree of public/private control' have been chosen as the defining criteria.

The government controlled organisations range from Bord Fáilte and CERT at the national level to Regional Tourism Organisations (RTOs) and down to the local Tourist Information Office (TIO). Also included in the national, government-funded/controlled category are non-tourism organisations which include the Office of Public Works and TEAGASC, which are not specifically tourism organisations, but carry out tourism related functions.

The 'Other Tourism Organisation' category includes the Irish Hotels Federation, Convention Bureau of Ireland, Coach Tourism Council, and the Irish Tourist Industry Confederation. The 'Specialised Tourism Organisation' category includes voluntary specialist groups, such as Irish Farm Holidays, Town and Country Homes, Hidden Ireland and Friendly Homes of Ireland which are independent organisations which actively promote their members.

At a regional level for non-governmental organisations is the Shannon Tourism Partnership, which is a regional marketing partnership. While this organisation is sponsored by Shannon Development, the MidWestern regional tourism organisation it places strong emphasis on the involvement of its members. The next level is 'Lough Derg Organisation' which includes the Lough Derg Working, and Marketing Groups. 'Sub-Lake Groups' includes Tipperary Lakeside and the East Clare LEADER group. The final organisation in this model is the most localised and non-government category which contains Nenagh Heritage Centre.

This model represents the importance which the individual operators place on their contact with the agencies and organisations in question. For example 67.3 percent of all operators contacted the Regional Tourism Organisation, but 96.6 percent of those operators contacted the organisation on a regular basis.

The overall trend in the model is that the most frequently contacted groups are the local agencies, both governmental and non-governmental. The most frequently contacted group was the aforementioned Regional Tourism Organisation (mainly Shannon Development), and also in this category are the local tourist information office and the 'Sub-Lake Groups' (Tipperary Lakeside and LEADER). The least contacted organisations are the Shannon Tourism Partnership, the 'Other Tourism Group' and the 'Specialised Tourism Groups'. This model visually demonstrates the findings of Table 2, that the most regular IORs between operators and organisations occur where the interaction has a visible and direct purpose in relation to the work of the tourism operator. Thus, contact with the local level marketing groups is prominent, while the lowest incidence of contact is with organisations which collect subscriptions and have little reason to engage in active day-to-day contact with operators.

\section{Lough Derg Marketing Effectiveness Model}

The structure of the model in Figure 4 is similar to Figure 3, but, in this case it represents the IORs between Lough Derg operators and the main tourism marketing groups. As with the previous model, the vertical axis in this model deals with the scale of organisations, ranging from national to local level. The horizontal axis represents the level of specialisation of the organisation, ranging from the specific or elite organisations, to the more general, which deal with any tourism type. In this case the model illustrates the 


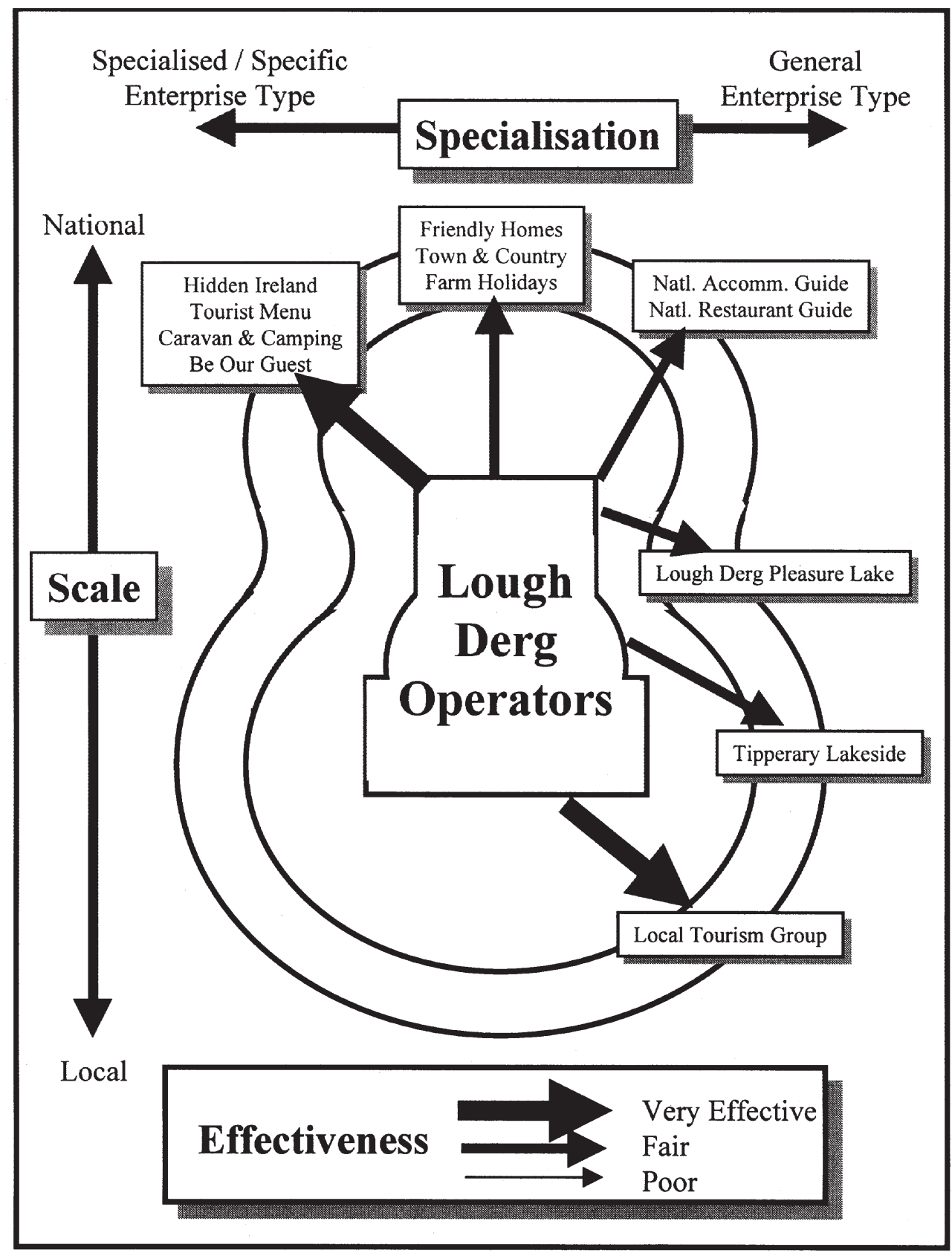

Figure 4: Marketing IORs in Lough Derg tourism. 
operators' perceived effectiveness of the various IORs.

Using these defining criteria, the 'external coalition' in the model is made up of six categories of marketing organisation. The first contains highly specialised organisations which are national in scale and includes Hidden Ireland, Tourist Menu, the recognised Caravan and Camping Guide and the 'Be our Guest' group. Slightly less specialised organisations such as Friendly Homes of Ireland, Town and Country Homes and Farm Holidays are in the next category, while the more generalised advertising organisations such as the Ireland Accommodation Guide and the Ballygowan Guide to Restaurants are in the third category. All three of these groups are national in scale, but vary in their level of specialisation or member selection. None of the operators deal with specialised local marketing organisations, but, a number of less specialised local agencies exist which deal with a variety of tourism enterprises either around the entire lake (Lough Derg Pleasure Lake - an advertising group); portions of the lake (Tipperary Lakeside - an areabased development group with tourism interests) or localised tourism groups (Scarriff LEADER group and Portumna Tourism Group)

The figure illustrates the opinion of Lough Derg operators regarding the effectiveness of the various categories of organisation which they contact for marketing purposes. All organisations are perceived to be at least fair in their effectiveness, but, there is a tendency for national agencies which are specialised and local groups (which are not specialised) to be seen as the most effective in their marketing work.

\section{Formalisation and Reciprocity of IORs}

The above methods of examining tourism IORs around Lough Derg illustrate the complex set of relationships which exist between a sample of Irish tourism operators and the organisations which support them. As mentioned, 82.7 percent of operators in this survey contact at least one organisation for some business related purpose. Many operators contact more than one organisation, and the main reasons they cite for such contacts are for marketing purposes and advertising, advice on day-to-day running of their businesses and interest in their locality. Various reasons were given by operators for not being in contact with more organisations, but the main reason was 'lack of time' (41.0 percent of operators). With this in mind, the following model (Figure 5) suggests an overall organisational structure for the Lough Derg area which rationalises the work being carried out by many of the organisations and groups. The proposed structure suggests some minor alterations in operation for some organisations, the need for major restructuring of others, and in some cases suggests the need for the establishment of new organisations.

A number of community groups already exist throughout the area and, in some cases, the work being done is highly successful. Community activity ranges from Tidy Town and other developmental work, to promotion of the local area through the publication of booklets and brochures. Many groups are informal in nature but nevertheless are voicing the opinion of their members and dealing with issues which they see as relevant. The establishment of groups in all communities throughout the area is a priority, as it is only through the existence of such groups that community action, responding to community issues, can be ensured (Griffin, 1995).

These community groups should feed into local groups, and a number of examples of successful local groups exist around Lough Derg: Tipperary Lakeside, Portumna Tourism Group and East Clare LEADER are seen by operators as being the most successful local level groups in the area. The ideal situation would be a small number of local groups around the lake which would cover the entire geographical area and work together in an integrated rather than conflicting manner. These groups should be of sufficient scale to act in a practical, professional and effective manner, and represent their members and the community groups in their catchment area when dealing with national or regional bodies.

Two main tourism organisations exist in the Lough Derg area: the Lough Derg Working Group and the 
Lough Derg Marketing Group. The Lough Derg Working Group, consisting mainly of statutory agencies, needs to encourage the regional public sector groups to become more actively involved in its operation. The position of the Working Group would be strengthened by the formalisation of its status and functions and its integration with the overall planning of tourism in the region.

Of all the organisations, the Lough Derg Marketing Group needs to undergo the most radical change. The group is currently restricted by its function and title and the adoption of a new title and wider responsibilities would provide greater appeal amongst tourism operators and thereby, achieve more successful results.

The model (Figure 5) proposes the replacement of the Lough Derg Marketing Group with a Tourism

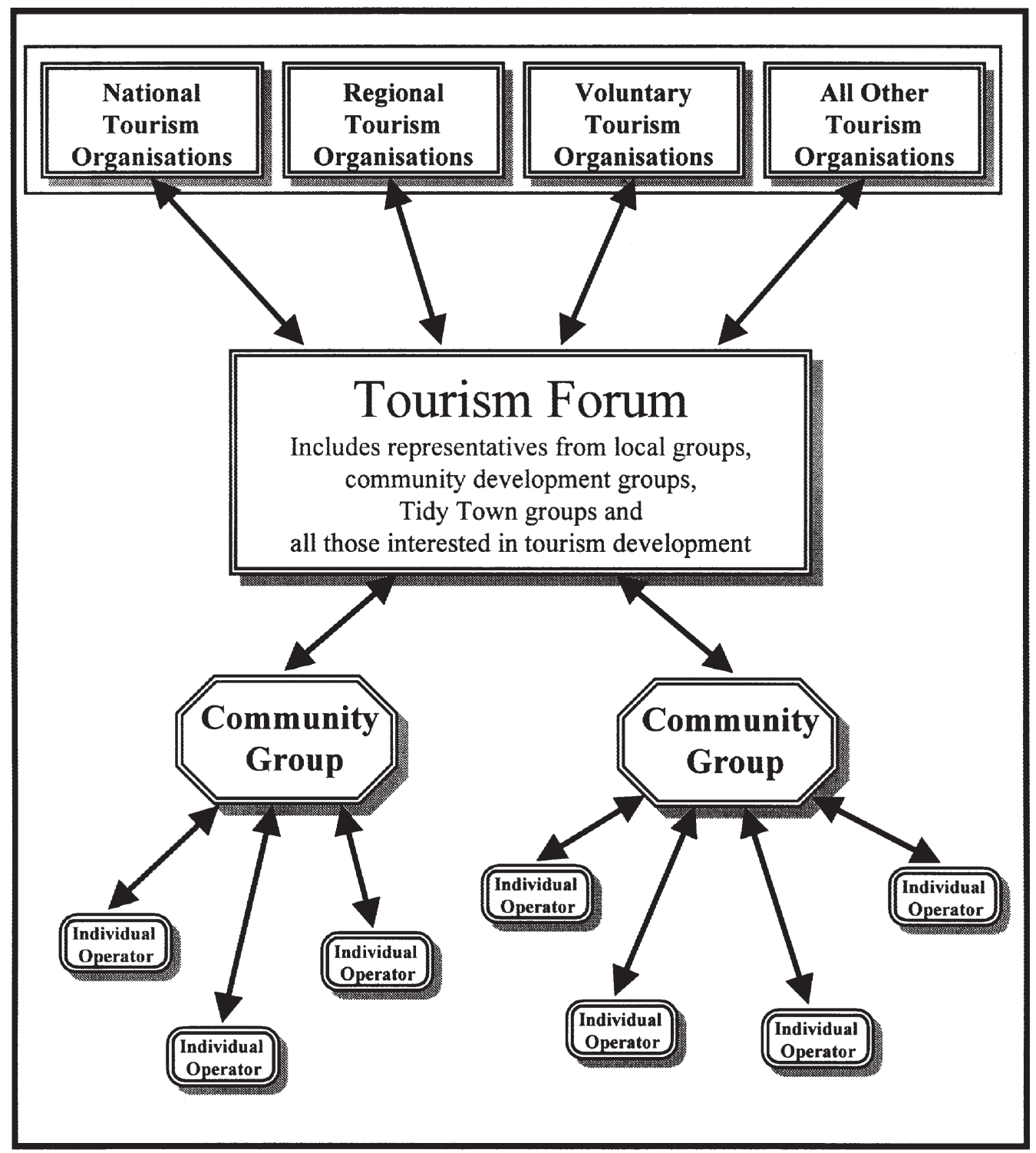

Figure 5: Proposed structure of Irish Tourism organisation. 
Forum. This new organisation would draw its membership from all interest groups and individuals, who are concerned about Lough Derg tourism. The main work of the Forum would be to act as facilitator between community/local tourism groups and national/regional tourism organisations. This work would be carried out while keeping cognisance of the overall developments around the lake, including the work of its parent agency, the Lough Derg Working Group.

Arising from this structure, sub-groups and committees could be formed consisting of members from the public sector and from all bodies and community groups to tackle mutual issues of concern such as monitoring and control of pollution and the overall development of the lake. Providing such consultation between the community and regional/national policy makers would ensure a more viable and informed planning process, and would provide the reformed 'marketing' group with a stronger focus.

As part of this restructuring, it is suggested that it is not entirely feasible for a lake-wide organisation to successfully engage in the marketing of tourism. This is in agreement with the findings of Drea (1992), who suggests that marketing should be a higher level activity, as the proliferation of local level organisations engaging in marketing functions is not conducive to the creation of a national image abroad. Therefore, the main potential for the suggested Lough Derg Tourism Forum would be in the area of product development and planning rather than marketing.

There are two main strengths in this model; first, it formalises and thereby rationalises IORs and secondly, it allows for a two-way transfer (reciprocity) of ideas and information. Where appropriate, this structure could interact with other regional or national organisations, thus rationalising resources such as time and money spent in contact with the multitude of organisations outlined above. For example, organisations such as Irish Farm Holidays or the Ireland Accommodation Guide could contact, or be contacted by, the Tourism Forum which would act on behalf of its members (Griffin, 1995).

\section{Conclusion}

By applying the aforementioned theoretical models in the analysis of Lough Derg tourism, it can be seen that organisations which tourism operators perceive as being effective and organisations which they contact regularly, exhibit a number of common traits. These traits may be seen as prerequisites for successful IORs in Irish tourism and while none of the Lough Derg tourism organisations possess all of these traits, those which are closer to the ideals of these indices, are perceived by operators as being most useful in the organisation of tourism.

(1) They deal with operators on a personal basis (Shannon Development, for example, claim to know, the majority of tourism operators in their area, such knowledge should help their operations).

(2) They interact with operators and offer an opportunity for members to voice their opinion (organisations such as Irish Farm Holidays encourage involvement from their individual members).

(3) They are specialised and/or successful in the work they carry out (Hidden Ireland allows only specific types of enterprises to join and thus the advertising carried out is of a highly specialised nature).

(4) The work they carry out is directly relevant to their members/businesses which contact them (East Clare LEADER, for example, has carried out small business training courses in direct response to their members' needs) (Griffin, 1995).

As such these traits may be considered as 'ideals for IORs' or the core of a blueprint for tourism organisations in their dealings with tourism operators.

Through the use of models, this paper has brought together a number of key concepts regarding the IORs in tourism around Lough Derg. Examination of these concepts illustrates the need for the principal tourism organisations to co-ordinate their work, to consult with the individual tourism operators and to 
tailor their work to the needs of their members. Ideals for the operation of tourism organisations have been proposed, and a suggested revision of the present structures around Lough Derg has been put forward.

The focus of recent tourism investigation has neglected the organisational aspect of the activity. Bringing together the results of consultation with tourism operators, this work has formulated a series of ideals and structures for the reorganisation of Lough Derg tourism. It is suggested, however, that these proposals could be applicable in a much broader context, and even adopted at a national scale. While Irish tourism continues to expand, one is reminded of Gillmor's comments: "although the need for organisational structures is particularly great in tourism, their provision is comparatively recent. They have developed with the expansion of the industry and with the growing realisation of its importance and the need for organisation" (1985: 305). Clearly the recent expansion of tourism in Ireland has not been matched by an equivalent evolution of organisational structures. This paper has suggested a formula for such development which would lead to a more efficient and successful operation and organisation of Irish tourism.

\section{References}

BDO SIMPSON XAVIER CONSULTING (1998) Employment Survey of the Tourism Industry in Ireland. Dublin: Council for Education, Recruitment and Training for the Hotel, Catering and Tourism Industry.

BORD FÁILTE (1995) Tourism Facts 1994. Dublin: Bord Fáilte.

BORD FÁILTE (1998) Tourism Facts 1997. Dublin: Bord Fáilte.

CLEGG, S.R. (1990) Modern Organisations. London: Sage Publications.

DEEGAN, J. and DINEEN, D.A. (1997) Tourism Policy and Performance: the Irish Experience. London: International Thomson.

DEPARTMENT of TOURISM and TRANSPORT (1992) First Operational Programme for Tourism 1989-1993. Dublin: Stationery Office.

DEPARTMENT of TOURISM and TRANSPORT (1994) Second Operational Programme for Tourism 1994-1999. Dublin: Stationery Office.

DREA, S. (1992) The Structural Organisation of Irish Tourism. Unpublished MA thesis. Maynooth: National University of Ireland, Maynooth.

FLANAGAN, S. (1992) The role of tourism strategy planning with special reference to the Midlands-East region, In: Feehan, J. (ed.) Environment and Development in Ireland. Dublin: Environmental Institute, University College Dublin.

GILLMOR, D.A. (1985) Economic Activities in the Republic of Ireland: A Geographical Perspective. Dublin: Gill and Macmillan, 302-337.

GRIFFIN, K. (1995) The Operation and Organisation of Irish Tourism : Lough Derg a Local Study. Unpublished MA thesis. Maynooth: National University of Ireland, Maynooth.

HALL, R.H. (1991) Organisations: Structures, Processes and Outcomes. New York: Prentice Hall.

IRISH TOURIST BOARD (1998) A Business Plan for Irish Tourism Marketing 1998-2003. Dublin: Bord Fáilte.

IRISH TOURIST INDUSTRY CONFEDERATION (1998) Strategy for Growth Beyond 2000 : a Strategic Framework for Tourism. Dublin: Irish Tourist Industry Confederation.

PEARCE, D.G. (1992) Tourist Organisations. New York: Longman Scientific \& Technical.

SIMMONS, D.G. (1994) Community Participation in Tourism Planning, Tourism Management, 15(2), 98-108.

SMITH, V. L. (1992) Hosts and Guests Revisited, American Behavioural Scientist, 36(2), 187-199. 